\title{
Antioxidant and Biological Activities of Three Morphotypes of Murraya koenigii L. from Uttarakhand
}

\section{Sivakumar ChV*and Meera I}

Instrumental Methods of Analysis Lab, Department of Biotechnology, The ICFAI University, Dehradun-248197, India

\begin{abstract}
The antioxidant activities of three morphotypes of Murraya koenigii $\mathrm{L}$ were evaluated by ABTS and phosphomolybdenum assays along with plant polyphenolic constituents and reference antioxidants. All examined methanolic extracts showed significant activity to scavenge ABTS and hydroxyl free radicals, reducing power, iron chelating ability and total antioxidant capacity in the order: Brown>Dwarf>Regular. Total polyphenol content (111$532 \mathrm{mg} / \mathrm{g}$ ), flavonoid $(0.01-0.09 \%)$ contents in dried plant samples was determined spectrophotometrically. The present study indicates the value of Murraya koenigii $\mathrm{L}$ as good source of antioxidants especially brown type.
\end{abstract}

Keywords: Murraya koenigii; Morphotypes; Antioxidants; Flavonoids

\section{Introduction}

The chemically unstable free radicals cause damage to proteins, DNA, lipid cells as a result of imbalance between the generation of reactive oxygen species (ROS) and the antioxidant enzymes [1]. Free radicals are part of aerobic life generated at low level during physiological functions [2]. They are known to revoltingly implicate in the pathogenesis of various diseases such as cancer, diabetes, cardiovascular diseases, aging, oxidative stress and metabolic syndrome. These radicals include superoxide anions, hydroxyl, nitric oxide and hydrogen peroxide radicals [3,4]. Antioxidants of natural and synthetic origin prevent the free radical damage by its protective role such as reacting with them, chelating catalytic metals and by playing as oxygen scavengers. In the intervening time, the ingestion of several synthetic antioxidants such as BHT and BHA has been reported toxic to man [5]. The importance towards natural antioxidant has now drawn attention and different kinds of plants and its parts have already been proved as natural antioxidant sources [6].

Murraya koenigii L belong to family Rutaceae, a perennial shrub or small tree commonly cultivated in India, Srilanka and other Asian countries [7]. It is locally known as curry leaf plant due to presence of aromatic smell, ornament and used as a natural flavoring agent for various food preparations [8]. Leaves have somewhat pungent, bitter and weakly acidulous taste and these characteristics retained after drying. The leaves are highly valued as seasoning along with sliced onions in Indian and Asian countries cooking. Fresh leaves dried powder and volatile oils are comprehensively used in India to provide flavor in many food dishes preparation and materials [9,10].Oil used in soap and cosmetic industries [11]. The presence of four chemo types' $\beta$-pinene, $\alpha$-pinene, $\beta$-caryophyllene, $\beta$-phellandrene are reported in India [12]. It is also having ability to control the spoilage of food used only or by synergistically combination mixture [13]. Murraya koenigii $\mathrm{L}$ can be propagated by mounting the small suckers from the base of the tree, by root cutting, or by seed propagation.

M. koenigii L. in India used as herb in Ayurvedic medicine preparations. Leaves and roots can be used to cure piles and relieve heat of the body, dehydration, tenderness and itching. It has been reported previously that much valued as an anti-diabetic [14], antioxidant [15], antifungal, antimicrobial, cytotoxic properties [16], anti inflammatory, antitumor promoting [17], anti-hypercholesterolemic, kidney pain- relief, hepatoprotective activities. Murraya koenigii L is recognized to be the good source of carbazole alkaloids. The other phytochemicals isolated and characterized so far from the leaves are alkaloids such as mahanine [18], koenine, koenigine, koenidine [19], girinimbiol, girinimibine [20], koenimbine, O-methyl murrayamine A, O-methyl mahanine, isomahanine, bismahanine, bispyrayafoline [21] and rich source of iron. It is also reported to contain 5,8-dimethylfuranocoumarin, 1-al, 3 [6', 6' dimethyl 5-hexene] carbazole and $\beta$-sitosterol [22].

Uttarakhand state covers an area of 53,485 sq. km., accounts for almost $15.5 \%$ of the total geographical area of Western Himalayas. The majority of the northern places of the state are covered by the Himalayan ranges and glaciers, while the lower reaches are densely forested. Due to these immense altitudinal variation, extensive array of climatic zones are available, which favors the luxuriant growth of diversified and rich vegetation. The authors examined/ collected and identified Murraya koenigii L comes in three different morphotypes in respect to color, size of leaves, habitat of plant, flavor of the plant and named such as Brown/Gamthi (GM), regular (RE) and Dwarf (DF). Regular type grows as tall and is the fastest growing plant, great looking and leaves, exstipulate, bipinnately compound, long, having reticulated venation with dark green color available in all over India. Dwarf type grows as shrub with branches are spread and appears as bushy and leaves are light green, look like regular with little taller with aromacity of its own. Gamthi/Brown type is most fragrant very thick smallest leaf structure but slowest of all the curry trees. Leaves edges are serrated are the most flavor and they are smaller and dark brown in color. All the three morphotypes of curry leaf plant differ in the intensity of flavor.

The objective of this study was to investigate the variations in antioxidant and other biological properties of three morphotypes.

*Corresponding author: Sivakumar ChV, Instrumental Methods of Analysis Lab Department of Biotechnology, The ICFAI University, Dehradun-248197, India, E-mail: siva.bioteck@gmail.com

Received April 16, 2013; Accepted June 24, 2013; Published July 01, 2013

Citation: Sivakumar ChV, Meera I (2013) Antioxidant and Biological Activities of Three Morphotypes of Murraya koenigii L. from Uttarakhand. J Food Process Technol 4: 246. doi:10.4172/2157-7110.1000246

Copyright: (C) 2013 Sivakumar ChV, et al. This is an open-access article distributed under the terms of the Creative Commons Attribution License, which permits unrestricted use, distribution, and reproduction in any medium, provided the original author and source are credited. 


\section{Materials and Methods}

Ultra pure water used for bioassays was prepared in-house using a Sartorius arium 611 UF water purification system. Solvent (Methanol) used for extraction were of HPLC grade and were purchased from Merck. Folin-Ciocalteu's phenol reagent was purchased from SRL (Mumbai). Ferrozine was procured from Himedia (India). ABTS- 2, 2 azinobis-(3ethylbenzthiazoline-6-sulfonic acid) chromophore, Diammonium salt was procured from EMD Biosciences Inc, USA. Gallic acid (Himedia), $\mathrm{H}_{2} \mathrm{O}_{2}$ (Merck), L-Ascorbic acid (Merck), Potassium persulfate (Sisco) is obtained from respective manufacturer. The Perkin Elmer (Lambda 25 Model) double beam UV-Vis spectrophotometer was used for determination of absorbance of the solution with $10 \mathrm{~mm}$ matched quartz cuvettes. The $\mathrm{pH}$ meter (Systronics) with calomel electrode was used. All chemicals and reagents used in the experiments were of analytical grade.

\section{Sample collection preparation and extraction process}

The three different types of Murraya koenigii L personally collected in hill area of Uttrakhand (India) and were kept for air dry after initial washing with double distilled water on the same day. The dried leaves were ground to powder using laboratory blender on medium speed. 1:20 ratio of powder and methanol was transferred into reflux apparatus and maintained for six hours at boiling temperature. The extracted solvent was allowed to evaporate to dryness under vacuum on a rotary evaporator at $40^{\circ} \mathrm{C}$. The obtained gooey dried residues of three types were subsequently reliquefied in methanol for total polyphenolics and other biological activities. All the extracts were used to filter through a Whattman filter No land were stored at $-20^{\circ} \mathrm{C}$ till usage.

\section{Total polyphenol content (TPC)}

TPC of the extracts were measured using spectrophotometric Folin-Ciocalteu method as described by Singleton et al [23]. FolinCiocalteu phenol reagent method is used to obtain a crude estimate of the amount of phenolic compounds which undergo a complex redox reaction with phosphotungstic and phosphomolybdic acids present in the reagent followed by measuring the absorbance of coloured solution at $725 \mathrm{~nm}$. Gallic acid was used as standard. 10-50 $\mu \mathrm{g} / \mathrm{mL}$ standard solutions of gallic acid were prepared by using $1 \mathrm{mg} / \mathrm{mL}$ of gallic acid stock solution prepared using extracting solvent. The extract was prepared at concentration of $1 \mathrm{mg} / \mathrm{mL}$. The reaction mixture was prepared by mixing $0.5 \mathrm{~mL}$ of extract, $2.5 \mathrm{~mL}$ of $10 \%$ Folin-Ciocalteus reagent prepared in water and $2.5 \mathrm{ml} 7.5 \% \mathrm{NaHCO}_{3}$ and mixed gently. Blank was simultaneously prepared, containing methanol in place of extract. After standing at room temperature for $60 \mathrm{~min}$, the absorbance was read at $725 \mathrm{~nm}$ using double beam Perkin Elmer Lambda 25 UV/Vis spectrophotometer. The standard calibration curve of gallic acid $(0.01-0.05 \mathrm{mg} / \mathrm{mL})$ was plotted. All samples and readings were prepared and measured in triplicate. Phenolic content of extracts was expressed in Gallic acid equivalents (GAEmg/mL).

\section{Flavonoids content}

The amount of flavonoids was determined using Aluminium chloride spectrophotometric method [24] with little modifications. The basis of this assay is that Aluminium chloride forms acid stable complexes with the C-4 keto group and either the C-3 or C-5 hydroxyl group of flavones and flavonols. In addition it also forms acid labile complexes with the ortho-dihydroxyl groups in the A or B ring of flavonoids. Plant extract $(1 \mathrm{ml} \mathrm{of} 1 \mathrm{mg} / \mathrm{ml})$ in methanol were separately mixed with $0.5 \mathrm{ml}$ of methanol, $1 \mathrm{ml}$ of $2 \%$ aluminium chloride, 0.1 $\mathrm{ml}$ of $1 \mathrm{M}$ potassium acetate and $2.8 \mathrm{ml}$ of distilled water. The samples were incubated for an hour at room temperature. The absorbance was determined at $\lambda \max =415 \mathrm{~nm}$. The samples were prepared in triplicate and the mean value of absorbance was obtained. The same procedure was repeated for the rutin and the calibration line was construed. Concentration of Flavonoids in extracts was expressed in terms of rutin equivalent (mg of Ru/g of extract).

\section{Reducing potential assay}

The reducing power of three types of Murraya koenigii L. methanolic extract was determined by Oyaizu method [25] in which Substances, which have reduction potential, react with potassium ferricyanide $\left(\mathrm{Fe}^{3+}\right)$ to form potassium ferrocyanide $\left(\mathrm{Fe}^{2+}\right)$, which then reacts with ferric chloride to form ferric ferrous complex that has an absorption maximum at $700 \mathrm{~nm}$. The different concentration of extract (10-50 $\mu \mathrm{g} / \mathrm{mL}$ ) in the test tube was mixed with $2.5 \mathrm{~mL}$ of $0.2 \mathrm{M}$ phosphate buffer $(\mathrm{pH}=6.6)$ and $2.5 \mathrm{~mL}$ of $1 \%$ potassium ferricyanide $\left[\mathrm{K}_{3} \mathrm{Fe}(\mathrm{CN})_{6}\right]$ solution. The mixture was incubated at $50^{\circ} \mathrm{C}$ for $20 \mathrm{~min}, 2.5 \mathrm{~mL}$ of $10 \%$ Trichloroacetic acid was added to mixture and centrifuged at $3000 \mathrm{rpm}$ for $15 \mathrm{~min}$. The upper layer of supernatant $(2.5 \mathrm{~mL})$ was mixed with $2.5 \mathrm{~mL}$ of distilled water and $0.5 \mathrm{~mL}$ of $0.1 \% \mathrm{FeCl}_{3}$ and the absorbance was measured using double beam spectrophotometer at $700 \mathrm{~nm}$. L-Ascrobic acid was used as reference standard and phosphate buffer used as blank. Increased absorbance of the reaction mixture indicated potency of reducing power. All samples and readings were prepared and measured in triplicate.

\section{Iron chelation activity}

The chelating effect on ferrous ions was determined according to the method of Dinis [26] with little modifications. The principle was that the Ferrozine reagent can quantitatively form complexes with $\mathrm{Fe}^{2+}$. In the presence of chelating agents, the formation of complex is disrupting, results in decrease of the colored complex and its measurement is the potential of the metal chelating activity. The three extracts were tested; each test solution was prepared by mixing $0.25 \mathrm{~mL}$ of extract at different concentration with $0.06 \mathrm{~mL}$ of $2 \mathrm{mM} \mathrm{FeCl}_{2}$. This was followed by the addition of $0.2 \mathrm{~mL}$ of $2 \mathrm{mM}$ ferrozine and finally the volume is increased by adding $4 \mathrm{~mL}$ of solvent, shaken and left to react at room temperature for $10 \mathrm{~min}$ before determining the absorbance of the mixture at $562 \mathrm{~nm}$. All samples are analyzed in triplicates and mean value was represented. The chelating effect (\%) was calculated as

$$
\text { Metal Chelating effects }(\%)=\% \text { Inhibition }=[(A 0-A 1) / A 0 \times 100]
$$

where $\mathrm{A}_{0}$ was the absorbance of the control/blank (without extract) and $A_{1}$ was the absorbance of the extract or standard.

\section{Hydroxyl radical scavenging activity assay}

The three types scavenging activity for hydroxyl radicals were calculated with Fenton reaction [27]. Hydroxyl radicals was generated in vitro by mixing ferrous ion $\left(\mathrm{Fe}^{2+}\right)$ with hydrogen peroxide and 1,10-phenanthroline. Phenanthroline- $\mathrm{Fe}^{2+}$ is an indicator of redox reaction. The $\mathrm{H}_{2} \mathrm{O}_{2} / \mathrm{Fe}^{2+}$ system generate hydroxyl radicals through Fenton reaction and Phenanthroline- $\mathrm{Fe}^{2+}$ complex oxidises to $\mathrm{Fe}^{3+}$. Reaction mixture contained $60 \mu \mathrm{l}$ of $1.0 \mathrm{mM} \mathrm{FeCl}_{2}, 90 \mu \mathrm{l}$ of $1 \mathrm{mM}$ 1,10-phenanthroline, $2.4 \mathrm{ml}$ of $0.2 \mathrm{M}$ phosphate buffer ( $\mathrm{pH} 7.8$ ), $150 \mu \mathrm{l}$ of $0.17 \mathrm{M} \mathrm{H}_{2} \mathrm{O}_{2}$ and $1.5 \mathrm{ml}$ of extract at various concentrations. Adding $\mathrm{H}_{2} \mathrm{O}_{2}$ started the reaction. After incubation at room temperature for $5 \mathrm{~min}$, the absorbance of the mixture at $560 \mathrm{~nm}$ was measured with a double beam spectrophotometer. The hydroxyl radicals scavenging activity was calculated. 


$$
\% \text { Inhibition }=[(A 0-A 1) / A 0 \times 100]
$$

Where $\mathrm{A}_{0}$ was the absorbance of the control/blank (without extract) and $\mathrm{A}_{1}$ was the absorbance of the extract or standard.

\section{Scavenging of Hydrogen Peroxide}

The ability of the three types of Murraya koenigii L. to scavenge $\mathrm{H}_{2} \mathrm{O}_{2}$ was determined according to the method described by Ruch et al. [28]. The principle of this method is that there is a decrease in absorbance of $\mathrm{H}_{2} \mathrm{O}_{2}$ upon oxidation. A $2 \mathrm{mM}$ of $\mathrm{H}_{2} \mathrm{O}_{2}$ was primed in phosphate buffer ( $\mathrm{pH}$ 7.4) and concentration was determined spectrophotometrically at $230 \mathrm{~nm}$ (Perkin Elmer UV-Vis spectrophotometer). The different concentration of extract $(5-25 \mu \mathrm{g} / \mathrm{ml})$ in distilled water was added to a $\mathrm{H}_{2} \mathrm{O}_{2}$ solution $(0.6 \mathrm{ml}, 2 \mathrm{mM})$ and the absorbance of $\mathrm{H}_{2} \mathrm{O}_{2}$ at 230 $\mathrm{nm}$ was determined after $20 \mathrm{~min}$ against a blank solution in phosphate buffer without $\mathrm{H}_{2} \mathrm{O}_{2}$. The percentage of scavenging activity of $\mathrm{H}_{2} \mathrm{O}_{2}$ of Murraya koenigii L. and standard (Ascorbic acid) compounds was calculated by using the equation

$$
\% \text { Inhibition }=[(A 0-A 1) / A 0 \times 100]
$$

where $A_{0}$ was the absorbance of the control (blank, without extract) and $A_{1}$ was the absorbance of the extract or standard (Ascorbic acid).

\section{Molybdenum reduction potential}

The phosphomolybdenum reduction capacity of extracts was evaluated by using method according to the procedure of Prieto et al. [29]. This assay is based on the principle of reduction of Mo (VI) to Mo $(\mathrm{V})$ by the activity of antioxidant compounds and the subsequent formation of a green phosphate/Mo (V) complex at acidic $\mathrm{pH}$ with a maximal absorption at $695 \mathrm{~nm}$. A volume of $0.4 \mathrm{~mL}$ extract at concentration of $1 \mathrm{mg} / \mathrm{mL}$ was mixed with $4 \mathrm{~mL}$ of reagent. The reagent was prepared using $0.6 \mathrm{M}$ sulphuric acid, $28 \mathrm{mM}$ sodium phosphate, 4 $\mathrm{mM}$ ammonium molybdate. The tubes was covered and incubated in water bath at $90^{\circ} \mathrm{C}$ for $45 \mathrm{~min}$. bring down the temperature to Room temperature (RT) and absorbance was measured using double beam spectrophotometer at $695 \mathrm{~nm}$. The blank solution was prepared by adding $4 \mathrm{ml}$ reagent solution and an appropriate volume of the same solvent was used for the extract. The mean of the 3 readings was used and expressed as mg of ascorbic acid equivalents (AAE)/g extract.

\section{ABTS radical cation decolorization assay}

The ABTS cation radical scavenging action is known to be one of the various mechanisms for measuring antioxidant activity of foods. It is based on the neutralization of a radical-cation arising from the one-electron oxidation of the synthetic chromophore 2,2'azinobis(3-ethylbenzothiazoline-6-sulfonic acid) (ABTS ): ABTS*-e-ABTS ${ }^{*}$. This ABTS method determines the antioxidant activity of hydrogen donating antioxidants and of chain breaking antioxidants. This method was not only a rapid and reliable test of antioxidant capacity but also an advantageous assay applicable to both hydrophilic and lipophilic antioxidants/systems [30]. ABTS ${ }^{+}$radical stock solution was prepared by reacting $7 \mathrm{mM}$ ABTS (2,2'-azino-bis- (3-ethylbenzothiazoline-6sulfonic acid) and $2.45 \mathrm{mM}$ potassium persulphate $\left(\mathrm{K}_{2} \mathrm{~S}_{2} \mathrm{O}_{8}\right)$ in a ratio of 1:0.5 results incomplete oxidation and allocate the mixture to stand in the dark at room temperature for $12-16 \mathrm{~h}$ before use [31]. The stock solution was diluted with solvent and PBS ( $\mathrm{pH}$ 7.4) to give absorbance of $0.7( \pm 0.02)$ at $734 \mathrm{~nm}$ at RT. The radical decoloration assay was performed in a volume of $1 \mathrm{ml}$ of diluted $\mathrm{ABTS}^{+}$solution and $20 \mu \mathrm{L}$ volume of extract or standard compound (final concentration of 10$50 \mathrm{ug} / \mathrm{mL}$ ) and absorbance reading was recorded at RT accurately 1 min after initial mixing up to 20 min. Respective solvent blank was run and determinations were carried at least five times of standard and samples. The percentage inhibition of radical absorbance at $734 \mathrm{~nm}$ was recorded and $\mathrm{IC}_{50}$ values calculated

$$
\% \text { Inhibition }=[(A 0-A 1) / A 0 \times 100]
$$

where $A_{0}$ was the absorbance of the control (blank, without extract) and $A_{1}$ was the absorbance of the extract or standard.

\section{Results and Discussion}

\section{Total phenolic content}

Total phenolic content of methanolic leaf extract of three morphotypes of Murraya koenigii L. was estimated by Folin-Ciocalteu reagent and results were expressed as equivalents of Gallic Acid. Among three extracts, (Table 1) Gamthi typemethanolic extract has the more phenolic content over Dwarf and Regular methanolic extract. The phenolics are the well-known group of secondary metabolites and comprise a large group of biologically active compounds [32]. The antioxidant activities of phenols were credited to their redox properties, which permit them to act as reducing agents, hydrogen donators and singlet oxygen quenchers, as well as their metal chelating abilities. It was presented that phenol antioxidant index is a measure of quality antioxidant property of the leafy vegetable. The phenolic compounds exhibit scavenging efficiency of free radicals and reactive oxygen species was due to their phenolic hydroxyl groups that have the ability to scavenge radicals and widely distributed in plant kingdom [33]. The study of phenolics compound in food has been exhaustive after the investigation on red wine explained that moderate consumption of red wine which contains polyphenols help in the prevention of cardiovascular diseases [34]. Phenolic compounds also can do other biochemical activities such as antimutagenic, anticarcinogenic and the ability to modify expression of genes [35] (Figure 1).

\begin{tabular}{|c|c|c|c|}
\hline Extract & Yield (\%) & $\begin{array}{c}\text { Total Phenolic } \\
\text { Content }^{*}(\mathbf{m g} / \mathbf{g})\end{array}$ & $\begin{array}{c}\text { Total flavonoids content } \\
\text { (mg/g) }\end{array}$ \\
\hline Dwarf type & 4.8 & $168.2 \pm 2.58^{\mathrm{b}}$ & $4.82 \pm 1.58$ \\
\hline Regular type & 3.5 & $111.6 \pm 3.85^{\mathrm{a}}$ & $3.58 \pm 2.33^{\mathrm{a}}$ \\
\hline Gamthi type & 2.9 & $532.8 \pm 2.81^{\mathrm{c}}$ & $6.01 \pm 3.21^{\mathrm{b}}$ \\
\hline
\end{tabular}

*Values are means \pm SE of three experiments. Value with letters is significantly different $(p<0.05)$.

Table 1: Contents of phenolics, flavonoids in three morphotypes of Murraya koenigii L.

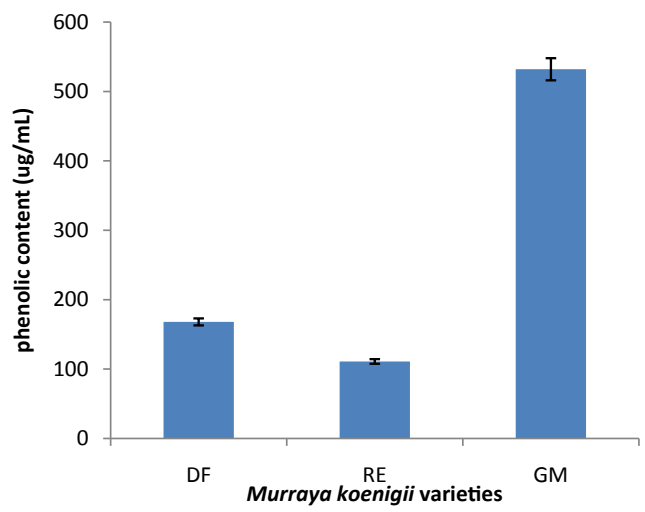

Figure 1: Phenol content of Murraya koenigii L. methanolic extracts in comparison form. 
Total polyphenols in all the methanolic extract samples was expressed in terms of gallic acid equivalents (GAE) with the standard curve equation of $\mathrm{y}=0.0018 \mathrm{x}-0.0042\left(\mathrm{r}^{2}=0.999\right)$. The chief criteria that distinguish the Gamthi extract from the regular and dwarf extracts is the former may contain more number of polyphenolic compounds and express the more quantity of phenolics production with more fragrance. However, it was not known whether the differences in the level of polyphenol detected are contributed or affected by presence and absence of more chlorophyll in the extract.

\section{Flavonoids content}

The flavonoids are important secondary metabolite of plant modulating lipid peroxidation involved in atherogenesis, thrombosis and carcinogenesis. It has established that pharmacological effect of flavonoids is associated with their antioxidant activities [36]. Murraya koenigii L. methanolic extract might be accredited to the high concentration of flavonoids so it can support for management of hypertension, obesity and diabetes and it also have been proved. The concentration of flavonoids in various methanolic plant extracts of the species M. koenigii L. was determined using spectrophotometric method with aluminum chloride. The amount of flavonoids in three types of Murraya koenigii L. ranged from 4-6 mg/g expressed in terms of rutin equivalent.

\section{Reducing potential assay}

The reducing power assay is used to test the reducing capability of the Murraya koenigii L. types leaf extracts to reduce the ferricyanide $\left(\mathrm{Fe}^{3+}\right)$ complex to their ferrous form $\left(\mathrm{Fe}^{2+}\right)$. The reducing power of the plant extract components might serve as a significant indicator of its potential antioxidant activity [37]. Higher reducing power might be accredited to higher amounts of phenolics, reductones and flavonoids and may reflect its antioxidant potential. Different studies have been pointed that the reducing property compounds are electron donors which may begene-associated which have been shown to exercise antioxidant action by breaking the free radical chain through the donation of a hydrogen atom [38]. Reducing power is normally linked with the occurrence of reductones which exert antioxidant action by breaking the free radical chain. Reductones can also reduce the oxidized intermediates of lipid peroxidation processes, so theycan act as primary and secondary antioxidants.

Figure 2 shows the plot of reducing power of three types of methanolic extracts incomparison form with each other. At different tested concentrations $(0.50-250 \mu \mathrm{g} / \mathrm{mL})$ all samples displayed the ability to reduce $\mathrm{Fe}(\mathrm{III})$ ions. The reducing power of the extracts increased with concentrations in a robust linear manner $\left(\mathrm{R}^{2}=0.82\right.$ 0.99). Gamthi displayed highest powerful effect in comparison with Dwarf and regular type.

\section{Iron chelation activity}

Iron is well-known for the formation of free radicals through the Fenton and Haber-Weiss reaction. Metal ion chelating activity of antioxidants in the extract stops the formation of oxyradicals and the resulting oxidative damage. Metal ion chelating property is a sign of antioxidant activity; it reduces the concentration of the catalysing transition metal in LPO [39]. It was investigated that chelating agent which can do $s$-bonds with a metal, are valuable as secondary antioxidants because they reduce the redox potential thereby stabilizing the oxidized form of the metal ion [40]. The chelating activity of ferrous ions by the three types extract of Murraya koenigii L. is shown in Figure 3. Ferrozine can quantitatively form complexes with $\mathrm{Fe}^{2+}$. In the presence of chelating agents, the formation of complex is disrupting, results in decrease of the colored complex and its measurement is the potential of the metal chelating activity. In this assay, all the three extracts and standard compounds interfered with the formation of ferrous and ferrozine complex, signifying the chelating activity. Gamthi methanolic extract may be explored clinical relevance in the treatment of iron-overload disorders such as thalassemia and results in the production of iron chelators due to its elevated chelating ability in vitro at low doses. Thalassemia is a genetically inherited blood disorders characterized by defective globin chain of haemoglobin and iron overload. Iron chelators from the plant methanolic extract will decrease iron availability in the blood circulation of thalassemic patients (Table 2).

\section{Hydroxyl scavenging activity}

Hydroxyl radical is animmensely reactive oxygen species,



Figure 2: Reducing power of Murraya koenigii L. methanolic extracts of different types.

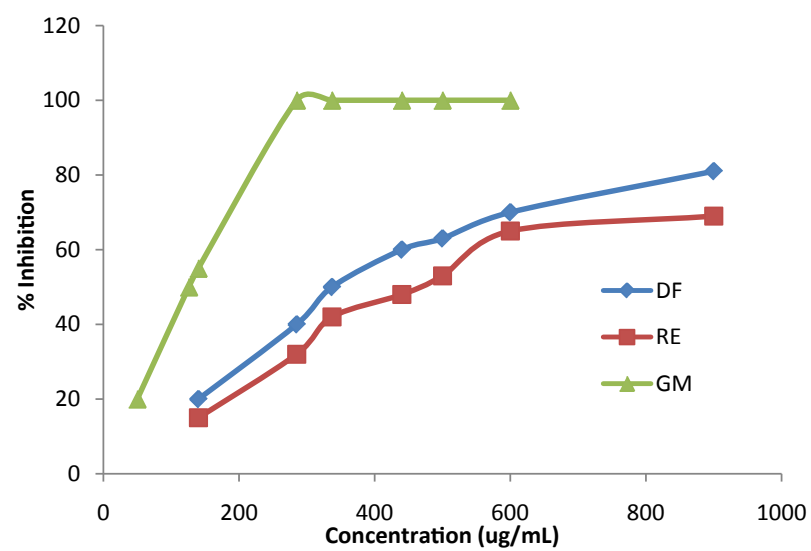

Figure 3: Iron(II) ions chelating activities of Murraya koenigii L. Methanolic extracts of selected types.

\begin{tabular}{|c|c|}
\hline Extract & IC $_{50}(\mathbf{u g} / \mathrm{mL})^{*}$ \\
\hline Dwarf type & $337 \pm 5.6 \mathrm{ug} / \mathrm{mL}$ \\
\hline Regular type & $452 \pm 12.5 \mathrm{ug} / \mathrm{mL}$ \\
\hline Gamthi type & $126.8 \pm 10.1 \mathrm{ug} / \mathrm{mL}$ \\
\hline EDTA & $13 \pm 0.9 \mathrm{ug} / \mathrm{mL}$ \\
\hline
\end{tabular}

${ }^{*} \mathrm{IC} \mathrm{C}_{50}$ value: concentration at which iron (II) ions were chelated by $50 \%$, respectively.

Table 2: Iron(II) ions chelating activities of methanolic extracts and a reference chelator. 
competent of modify numerous biological molecules in the cells. It can able to cause DNA damageby compete with deoxyribose for hydroxyl radicals leading to carcinogenesis, mutagenesis and cytotoxicity, capable of initiating the process of lipid peroxidation by abstracting hydrogen atoms from unsaturated fatty acids. They can also acquire hydrogen atoms from other biological molecules such as thiols, results to development of sulphur radicals which can do combine with oxygen to generate oxysulphur radicals, which damage biological molecules [41].

The radical scavenging capacity of three Murraya koenigii L. methanolic extracts, polyphenolic compounds are presented in Figure 4. All the extracts make use of inhibitory activities on the hydroxyl radical formation in a concentration relative manner. Among the studied plants, Gamthi showed the highest activity, with an $\mathrm{IC}_{50}$ value of $171 \pm 2.9 \mu \mathrm{g} / \mathrm{mL}$ and these results were in accordance with findings obtained by the ABTS assay. Moreover, the scavenging ability on hydroxyl radicals was in the order: Gamthi $>$ Dwarf $>$ regular. The $\mathrm{IC}_{50}$ value of Dwarf, Regular and rutin was $365 \pm 2.1 \mu \mathrm{g} / \mathrm{mL}, 471 \pm 1.8 \mu \mathrm{g} /$ $\mathrm{mL}$ and $28.5 \mu \mathrm{g} / \mathrm{mL}$, respectively.

\section{ABTS assay}

In present study, the three methanolic extracts of different cultivator types of Murraya koenigii L. showed notable $\mathrm{ABTS}^{+}$cation radical scavenging activity. The highest ABTS scavenging activity of Gamthi was attributed to the presence of higher levels of total phenolic compounds.

Figures 5-7 show the percent inhibition of ABTS radical scavenging activitywith experienced Murraya koenigii L. methanolic extracts compounds at different concentrations $(50-200 \mu \mathrm{g} / \mathrm{mL})$. The percentage of scavenging ABTS• of three plant extracts were $12-75 \%$ at concentration of $40 \mu \mathrm{g} / \mathrm{mL}$ respectively. Capability of the examined samples to scavenge ABTS- were evaluated on the basis of their $\mathrm{IC}_{50}$ values as they express the amount of the antioxidant needed to decrease the radical concentration by $50 \%$. The $\mathrm{IC}_{50}$ values obtained in this study are $81.6,118.4$ and $21.4 \mu \mathrm{g} / \mathrm{mL}$ of Dwarf, regular and Gamthi type of Murraya koenigii L. The scavenging effect of the samples on the ABTS radical was found in terms of Ascorbic acid equivalents: Gamthi>Dwarf $>$ Regular. Among the all tested plant samples, methanolic extract of $M$. koenigii gamthi exhibited the most effective radical scavenging activity $\left(\mathrm{IC}_{50}=21.4 \mu \mathrm{g} / \mathrm{mL}\right)$ which was alsosignificantly stronger $(\mathrm{p}<0.05)$ than other two samples. Thiscan be attributed mainly to higher phenolic

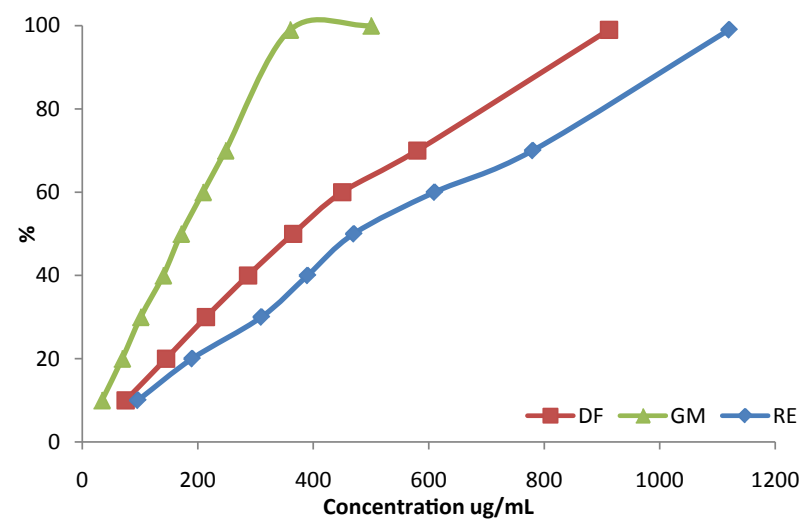

Figure 4: $\mathrm{OH}$ free radical scavenging effects of Murraya koenigii L. methanolic extracts.

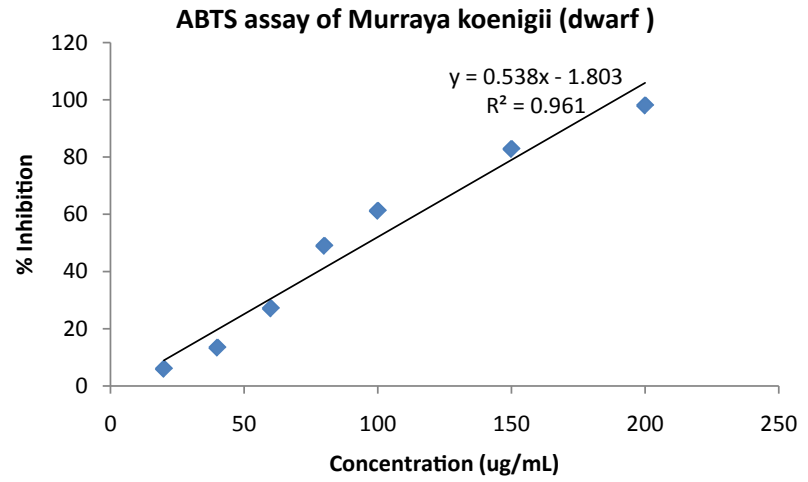

Figure 5: ABTS free radical scavenging effects of Murraya koenigii dwarf methanolic extract.



Figure 6: ABTS free radical scavenging effects of Murraya koenigii regular methanolic extract.

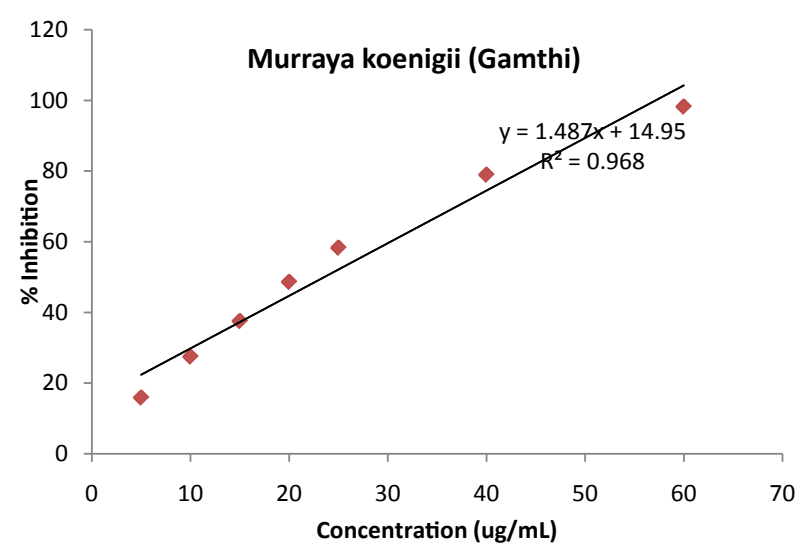

Figure 7: ABTS free radical scavenging effects of Murraya koenigii gamthi methanolic extract.

amount of plant especially phenolic acids, flavonoids than of other plant samples.

\section{Molybdenum reduction potential}

Total antioxidant capacities of three Murraya koenigii types of methanolic phenolic extracts in comparison between them were evaluated by phosphomolybdenum method. The calculated results are 
Citation: Sivakumar ChV, Meera I (2013) Antioxidant and Biological Activities of Three Morphotypes of Murraya koenigii L. from Uttarakhand. J Food Process Technol 4: 246. doi:10.4172/2157-7110.1000246

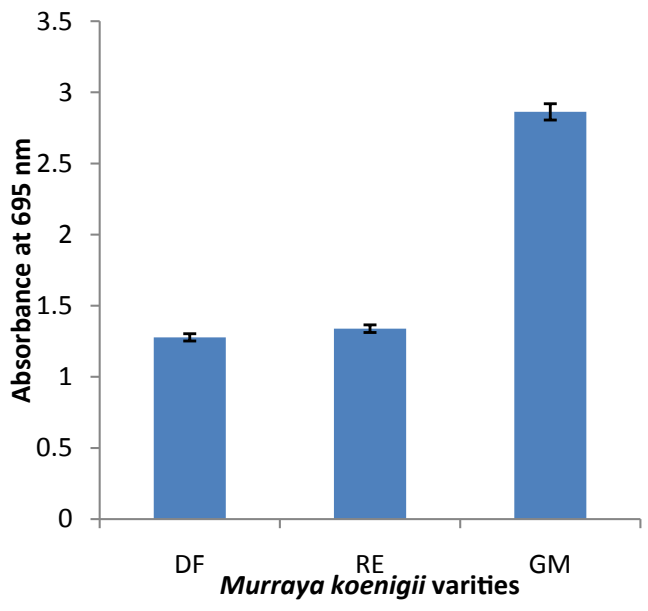

Figure 8: Antioxidant activity of Murraya koenigii selected types by molybdenum assay.

\begin{tabular}{|l|l|}
\hline Extract & Antioxidant activity (AAEmg/g) \\
\hline Dwarf type & $621.2 \pm 3.88$ \\
\hline Regular type & $641.6 \pm 2.15^{\mathrm{a}}$ \\
\hline Gamthi type & $1268.8 \pm 1.71^{\mathrm{b}}$ \\
\hline
\end{tabular}

* Values are means \pm SE of three experiments. Value with letters is significantly different $(p<0.05)$

Table 3: Antioxidant activity of Murraya koenigii selected types by molybdenum assay

expressed as ascorbic acid equivalents (AAE), are presented in Figure 8 and Table 3. Among the examined Murraya koenigii species, the highest total antioxidant capacity was found in M. Koenigii Gamthi with a value of $1268 \mathrm{AAE}$ per gram of extract.

\section{Conclusion}

In the present work, the comprehensive polyphenolic contents of M. koenigii three morphotypes species such as dwarf, regular and Gamthi with their related antioxidant activities were demonstrated for the first time. Our investigation results showed evidence that all the tested morphotypes are capable of directly quenching free radicals to cease the radical chain reaction, act as reducing agents, and chelating of transition metals to suppress the initiation of radical formation. Moreover, the Gamthi showed extensively high antioxidant activity than the other two morphotypes.

\section{References}

1. Manian R, Anusuya N, Siddhuraju P, Manian S (2008) The antioxidant activity and free radical scavenging potential of two different solvent extracts of Camellia sinensis (L.) O. Kuntz, Ficus bengalensis L. and Ficus racemosa L. Food Chem 107: 1000-1007.

2. Halliwell B (1991) Reactive oxygen species in living systems: source, biochemistry, and role in human disease. Am J Med 91: 14S-22S.

3. Raghuveer C, Tandon RV (2009) Consumption of Functional Food and Our Health Concerns. Pak J Physiol 5: 76-83.

4. Hosseinimehr SJ, Pourmorad F, Shahabimajd N, Shahrbandy K, Hosseinzadeh R (2007) In vitro Antioxidant Activity of Polygonium hyrcanicum, Centaureae depressa, Sambus ebulus, Menthe spicata and Phytolaceae Americana. Pak J Biol Sci 10: 637-640.

5. Lobo V, Patil A, Phatak A, Chandra N (2010) Free radicals, antioxidants and functional foods: Impact on human health. Pharmacogn Rev 4: 118-126.
6. Lobo V, Patil A, Phatak A, Chandra N (2010) Free radicals, antioxidants and functional foods: Impact on human health. Pharmacogn Rev 4: 118-126.

7. Anonymous (1962) The Wealth of India-Raw Materials. New Delhi: Publication and Information Directorate, CSIR.

8. Brandis D (1971) Indian trees and A count of Trees, Shrubs, Woody Climbers, Bamboos Plants Indigenous or Commonly Cultivated in the British Indian Empire, Dehra Dun, India.

9. Rao BRR, Rajput DK, Mallavarapu GR (2011) Chemotype Categorization of Curry Leaf Plants (Murraya koenigii (L.). Spreng.). J Essent Oil Bearing Plants 14: $1-10$.

10. Verghese J (1989) Indian curry leaf. Perf Flav 14: 69-70.

11. Lal RK, Khanuja SPS, Misra HO, Bansal K, Naqvi AA (2005) Genetic diversity in the secondary metabolite traits of curry leaf (Murraya koenigii (Linn). Spreng.) Indian Perfumer 49: 519-524.

12. Raina VK, Lal RK, Tripathi S, Khan M, Syamasundar KV, et al. (2002) Essential oil composition of genetically diverse stocks of Murraya koenigii from India. Flav Frag J 17: 144-146.

13. Dubey NK, Srivastava B, Kumar A (2008) Current Status of Plant Products as Botanical Pesticides in storage pest management. J Biopest 1: 182-186.

14. Arulselvan P, Ikumar GPS, Kumar SD, Subramanian S (2006) Anti-diabetic effect of Murraya koenigii leaves on streptozotocin induced diabetic rats. Pharmazie 61: 874-877.

15. Arulselvan P, Subramanian SP (2007) Beneficial effects of Murraya koenigi leaves on antioxidant defense system and ultra structural changes of pancreatic beta-cells in experimental diabetes in rats. Chem Biol Interact 165: 155-164.

16. Mackeen MM, Ali AM, El-Sharkawy SH, Manap MY, Salleh KM, et al. (1997) Antimicrobial and Cytotoxic Properties of Some Malaysian Traditional Vegetables (Ulam). Pharm Biol 35: 174-178.

17. Kok YY, Mooi LY, Ahmad K, Sukari MA, Mat N, et al. (2012) Anti-tumour promoting activity and antioxidant properties of girinimbine isolated from the stem bark of Murraya koenigii S. Molecules 17: 4651-4660.

18. Narasimhan NS, Paradkar MV, Kelkar SL (1970) Alkaloids of Murraya koenigii: Structures of mahanine, koenine, koenigine and koenidine. Indian J Chem 8 : 473-474.

19. Narasimhan NS, Paradkar MV, Chitguppi VP, Kelkar SL (1975) Alkaloids of Murraya koenigii: Structures of mahanimbine, koenimbine, mahanine, koenine, koenigine and koenidine. Indian J Chem 13: 993-999.

20. Adebajo AC, Avoola OF, Iwalewa EO, Akindahunsi AA, Omisore NO, et al (2006) Anti-trichomonal, biochemical and toxicological activities of methanolic extract and some carbazole alkaloids isolated from the leaves of Murraya koenigii growing in Nigeria. Phytomedicine 13: 246- 254.

21. Tachibana Y, Kikuzaki H, Lajis NH, Nakatani N (2003) Comparison of antioxidative properties of carbazole alkaloids from Murraya koenigii leaves. $J$ Agric Food Chem 51: 6461-6467.

22. Gupta S, Paarakh MP, Gavani U (2009) Isolation of Phytoconstituents from the leaves of Murraya koenigii Linn. Journal of Pharmacy Research 2: 1313-1314.

23. Singleton VL, Orthofer R, Lamuela-Raventos RM (1999) Analysis of tota phenols and other oxidation substrates and antioxidants by means of Folinciocalteu reagent. Methods Enzymol 299: 152-178.

24. Quettier-Deleu C, Gressier B, Vasseur J, Dine T, Brunet C, et al. (2000) Phenolic compounds and antioxidant activities of buckwheat (Fagopyrum esculentum Moench) hulls and flour. J Ethnopharmacol 72: 35-42.

25. Oyaizu M (1986) Studies on product of browning reaction prepared from glucose amine. Jap J Nutr 44: 307-315.

26. Dinis TC, Madeira VM, Almeida LM (1994) Action of phenolic derivates (acetaminophen, salicylate, and 5-aminosalicylate) as inhibitors of membrane lipid peroxidation and as peroxyl radical scavengers. Arch Biochem Biophys 315: $161-169$

27. Yu W, Zhao Y, Shu B (2004) The radical scavenging activities of radix puerariae isoflavonoids: A chemiluminescence study. Food Chem 86: 525-529.

28. Ruch RJ, Cheng SJ, Klaunig JE (1989) Prevention of cytotoxicity and inhibition of intercellular communication by antioxidant catechins isolated from Chinese green tea. Carcinogenesis 10: 1003-1008. 
Citation: Sivakumar ChV, Meera I (2013) Antioxidant and Biological Activities of Three Morphotypes of Murraya koenigii L. from Uttarakhand. J Food Process Technol 4: 246. doi:10.4172/2157-7110.1000246

Page 7 of 7

29. Prieto P Pineda M, Aguilar M (1999) Spectrophotometric quantitation of antioxidant capacity through the formation of a phosphomolybdenum complex specific application to the determination of vitamin E. Anal Biochem 269: $337-$ 341

30. Sasidharan I, Menon AN (2011) Effects of temperature and solvent on antioxidant properties of curry leaf (Murraya koenigii L.). J Food Sci Technol 48: $366-370$.

31. Re R, Pellegrini N, Proteggente A, Pannala A, Yang M, et al. (1999) Antioxidant activity applying an improved ABTS radical cation decolorization assay. Free Radic Biol Med 26: 1231-1237.

32. Dreosti IE (2000) Antioxidant polyphenols in tea, cocoa, and wine. Nutrition 16: 692-694.

33. Elliot JG (1999) Application of antioxidant vitamins in foods and beverages Food Technol 53: 46-48.

34. Marinova D, Ribarova F, Atanassova M (2005) Total phenolics and total flavonoids in Bulgarian fruits and vegetables. Journal of the University of Chemical Technology and Metallurgy 40: 255-260.

35. Nakamura Y, Watanabe S, Miyake N, Kohno H, Osawa T (2003)
Dihydrochalcones: evaluation as novel radical scavenging antioxidants. J Agric Food Chem 51: 3309-3312.

36. Shi J, Yu J, Pohorly J, Young CJ, Bryan M, et al. (2006) Optimization of the extraction of polyphenols from grapes seed meal by aqueous ethanol solution. Food Agric Environ 1: 42-47.

37. Meir S, Kanner J, Akiri B, Hadas SP (1995) Determination and Involvement of Aqueous Reducing Compounds in Oxidative Defense Systems of Various Senescing Leaves. J Agric Food Chem 43: 1813-1819.

38. Shimada K, Fujikawa K, Yahara K, Nakamura T (1992) Antioxidative properties of xanthan on the autoxidation of soybean oil in cyclodextrin emulsion. J Agric Food Chem 40: 945-948.

39. Duh PD, Tu YY, Yen GC (1999) Antioxidant Activity of Water Extract of Harng Jyur (Chrysanthemum morifolium Ramat). Food Sci Technol-LEB 32: 269-277.

40. Gordon MH (1990) The Mechanism of Antioxidant Action in vitro. London: Elsevier Applied Science, pp 1-18.

41. Aruoma OI (1998) Free radicals, oxidative stress, and antioxidants in human health and disease. J Amer Oil Chem Soc 75: 199-212. 